Authenticity in leadership: Reframing relational transparency through the lens of emotional labour

\author{
Steve Kempster \\ Lancaster University Management School \\ Marian Iszatt-White \\ Lancaster University Management School
}

And

Matt Brown

Lancaster University Management School

Corresponding Author:

Steve Kempster

Lancaster University Management School

Bailrigg

Lancaster

LA1 4YX.

s.kempster@lancaster.ac.uk

+441524594292 


\title{
Authenticity in leadership: Reframing relational transparency through the lens of emotional labour
}

\begin{abstract}
In this paper we problematize relational transparency as an element of authentic leadership when viewed through the lens of emotional labour. Using the method of analytic co-constructed auto-ethnography we examine a senior hospital manager's experience of seeking to be authentic during a period of intense challenge as he pursues the closure of a hospital ward. A first-person account is developed that speaks to the necessity of hiding felt emotions and displaying his perceptions of desired emotions warranted in the context in which he seeks to lead. That this is not experienced as inauthentic is seen as deriving from two dimensions of experienced authenticity: strength of identification with leadership role and fidelity to leadership purpose. The veracity of this reframing of authenticity in leadership practice is explored through a second study, of practising leaders required to balance the demands of performing emotional labour and appearing and feeling authentic. We suggest that reframing relational transparency as 'fidelity to purpose' may be a valuable counter-weight to the goal of relational transparency promulgated by the leadership industry and a practical advance for those seeking to practise authentic leadership.
\end{abstract}

Key words: Authentic leadership, emotional labour, role identification, relational transparency, fidelity to purpose. 


\section{Introduction}

The leadership industry has given much weight to the pursuance of authenticity as the sine qua non of leadership. The notion of relational transparency is a largely accepted cornerstone of authentic leadership (AL) and is all but ubiquitous in the AL literature. It is one of the four pillars of authentic leadership (see for example Walumbwa et al, 2008; Neider and Schreisheim, 2011) and has been present in the conceptual delineation of authentic leadership from its earliest roots, (Luthans and Avolio, 2003; Avolio and Gardner, 2005; Gardner et al, 2005). Much writing in the field draws on Harter's (2002) definition of authenticity, which stipulates the requirement for thoughts and feelings to be consistent with actions. Whilst significant scholarship has been devoted to the ever-more precise delineation of the construct - that is its antecedents and consequences, mediators and moderators - we would echo Tourish's (2015: 138) call for more work which 'problematize[s] core assumptions' in order to avoid trivial over-specification. Here we answer that call by problematizing the assumption of relational transparency in every day leadership practice.

We examine relational transparency through the lens of emotional labour (Hochschild, 1983) to offer a very different perspective on authenticity: identification with leadership role and fidelity to leadership purpose. By the former, we refer to the extent to which managers see their leadership role, and the behaviours through which they enact it, as part of who they are. The latter refers to their sense of acting in accord with specific goals to which they are committed and which they perceive as being their remit as a leader. These two orientations initially emerged from autoethnographic exploration with a senior manager leading under pressure, covering a period surrounding the closure of a hospital ward (referred to as Ward X). The value 
of the voice and insights of a single manager (as a co-constructed auto-ethnographic account) resonates with Van Maanen's proposal that the 'universal can be found in the particular' (2011: 229, original emphasis). The 'particular' is Matt's experience of seeking to be authentic whilst coping with continual demands to manage his emotional displays over an extended period. The 'universal' we seek to explore here is the phenomenon of relational transparency as an aspect of authenticity within every day leadership practice, as seen through the lens of emotional labour. It offers up a very different understanding of authentic leadership. This radical reframing was substantiated from a second study that investigated how middle and senior managers reconciled on a daily basis the requirement to perform emotional labour as part of their role with the desire to appear and feel authentic.

Our argument connects with recent work which problematizes the notion of authentic leadership as an enactment of the leader's essentialist 'true self' (Ford and Harding, 2011; Lawler and Ashman, 2012) and Bryant and Wolfram Cox's notion of emotional authenticity as 'a relational phenomenon' (2014: 719). Acknowledged to be a complex issue, studies have not explored how managers in the processes of leading seek to lesson aspects of felt inauthenticity in their everyday activities (Humphrey, Ashforth and Diefendorff, 2015). The question we seek to provide an insight into is, how do practising managers act authentically whilst undertaking activities that often limit the congruence of felt and exhibited emotions? We suggest that this question has been overlooked in the main as a result of methodological constraints on examining contextualised leadership practice associated with authenticity over an extended period. For example, issues of access are significant along with the difficulty of exploring emotions and authenticity with managers (Stormer and Devine 2008; 
Turnbull, 2012). We seek to address these access difficulties through the technique of co-constructed auto-ethnography (Kempster and Stewart, 2010).

The article is structured as follows. We first problematize the notion of relational transparency as an aspect of authenticity within leadership through examining the complex relationship between emotional labour and authenticity in the daily enactment of leading (Ingram and Iszatt-White, 2012). Second, we set out the methods and contexts for the two studies which underpin our work, and outline their respective roles in relation to our understanding of relational transparency and emotional labour. Third, a series of chronological vignettes form an aesthetic account of the closure of Ward $X$ that offers the reframing of authenticity related to strength of leadership role identification and the felt sense of fidelity to leadership purposes being pursued. Fourth, we present interview data from our second study which offers independent instantiation of this account through the accounts provided by 12 middle and senior managers from a range of different organisations and sectors. Finally, our discussion returns to the prevailing assumption of authenticity as relational transparency and explores the implications of our research for the development of theory associated with authenticity when anchored to leadership practice.

\section{Theoretical Context}

\section{Problematizing Authentic Leadership as Relational Transparency}

Prominent discourses of authentic leadership speak to a need for relational transparency and the maintenance of alignment between espoused values and behaviours/actions. Michie and Gooty assert that leaders should draw on 'selftranscendent values and act on them without emotional conflict $[. .$.$] in a way that$ makes their actions more consistent and authentic' (2005: 448). This assertion is 
echoed in related work that theorises aspects of authentic leadership as: acting in accordance with one's true self (Luthans and Avolio, 2003), being yourself (George, 2003); and being natural (Shamir and Eilam, 2005). Relational transparency is one of four components of the Authentic Leadership Questionnaire (Walumbwa et al, 2008), now a widely accepted instrument in the field, and was retained in later attempts to critique and revise the factor structure of this measure (Neider and Schriesheim, 2011). More recently, Algera and Lips-Wiersma (2012) observed that being true to 'self-in-relationship' is potentially more important as a component of authenticity then being true to self per se. Relational transparency is defined as 'valuing and achieving openness and truthfulness in one's close relationships' (Gardner et al, 2005: 357), and is seen as involving 'selective self-disclosure' (2005: 357). Early conceptualizations of authentic leadership likewise emphasized such components as consistency between values and actions (Sparrowe, 2005), self-expressive behaviour (Shamir and Eilam, 2005) and 'authentic behaviour/acting and authentic relational orientation' (Ilies et al, 2005: 373).

Authenticity in leadership relationships is not unproblematic however. The same definition cited above goes on to describe openness and truthfulness in terms of the 'free exchange of knowledge and information' (Gardner et al, 2005: 358, our emphasis). Thus whilst transparency in relation to the sharing of information is seen as a critical facet of authentic leadership, leaders are only required to be 'relatively transparent in expressing their true emotions and feelings to followers, while simultaneously regulating such emotions to minimize displays of inappropriate or potentially damaging emotions (2005: 358 , our emphasis). This appears to us to represent emotional labour by the back door and to raise significant questions as to who gets to decide what is appropriate/inappropriate and/or potentially damaging. 
Similarly, whilst emotional intelligence is suggested as being a necessary component of authentic leadership, as it contributes to self-awareness, its application is framed in terms of the 'effects of such emotions on cognitive processes and decision making' and 'the enhancement of leaders' abilities to display individualised consideration' (Gardner et al, 2005: 352). This suggests a rationalistic and instrumental approach to emotions that is not wholly congruent with relational transparency whilst not actually addressing the issues of emotion management.

Whilst emotions and emotion management are a frequent topic within the authentic leadership literature, their implications for relational transparency are underexplored in a number of significant respects. So, for example, Avolio et al (2004: 815) state that '[o]ur model proposes that authentic leadership influences followers' attitudes and behaviours through the key psychological process of identification, hope, positive emotions, optimism and trust' and suggest that authentic leaders are able to tap into emotions as 'a rich source of information' that 'can often alter followers' thinking and behaviour' (2004: 812). The issues raised here are twofold. Firstly, the emotions referred to are usually those of followers and appear detached from individual experience. We are told nothing about the emotions felt by leaders, or about the embodied experience of having emotions: rather they are a source of information or a lever for influencing behaviour. Secondly, in line with the positive psychological underpinnings of the authentic leadership construct, the emotions referred to are always positive: as Ford and Harding (2011: 467) note ' $[\mathrm{t}]$ here is no room, in this model, for self-knowledge to reveal anything that is not positive. The individual is not allowed a dark side.' We highlight that many of the propositions set out in early work on authentic leadership, including those in respect of relational transparency, remain 
untested. Their concordance with the daily experience of leaders remains to be confirmed.

The implications for relational authenticity of the self-regulation of individuals' expressive behaviour, in line with situational demands, are explored by Ilies et al (2005). They suggest the equating of high self-monitoring with inauthenticity: '[authentic leaders] expressive behaviour functionally reflects their own inner attitudes, emotions and dispositions' (Ilies et al, 2005: 380, citing Gangstead and Snyder, 2000: 531). Similarly, Michie and Gooty’s (2005) argument in favour of frequent experiences of positive other-directed emotions as an important determinant of authentic leadership, leaves blank the issue of how to be authentic if you don’t actually experience such emotions, or indeed when such emotions contravene social or workplace display rules (Ekman, 1992). It is similarly silent on whether it is enough to feel such emotions, or whether it is necessary for them to be displayed. Even where managers are transparent in expressing and acting in accord with their values (and emotions?) Eagly (2005) suggests that this is insufficient to constitute relational authenticity: they must also be accorded legitimacy to promote a set of values on behalf of the follower community they represent.

More broadly, Ford and Harding (2011) criticise authentic leadership as an idealised caricature that fails to recognise the complexities that the leader-follower relationship is situated within. Nyberg and Sveningsson (2014) suggest a paradox that leaders find themselves in, seeking to be authentic yet masking this in order to look like a good authentic leader. This intriguing idea of an authenticity paradox captures the essence of the tension of relational transparency - the idealised and romanticised follower expectations of a leader versus the open and honest exposure of, for example, manager's anxieties, fears, confusions, doubts, ignorance, vulnerabilities, pessimism 
and weaknesses. Tensions also come from organisational expectations of the roles and conduct to be performed by managers seeking to lead: for example, aspects of confidentiality may limit scope for transparency; decisions may need to be taken that conflict with follower needs and desires; and managers may be expected to align strategically with organisational goals. One might conclude that either authenticity as relational transparency is thus deeply flawed and problematic in the context of leadership practice, or that authenticity in the practice of leading has not been understood. When viewed through the lens of emotional labour there may be scope for such reframing.

\section{Emotional Labour as a Leadership Lens}

In her seminal work The Managed Heart Hochschild's (1983) articulation of emotional labour gives emphasis to an instrumental, exploitative economic tool made manifest through the highly prescriptive, usually one-off interactions familiar to us in the notion of 'service with a smile' (Humphrey, 2012; Humphrey, Pollack and Hawver, 2008). A more nuanced notion of service workers as 'skilled emotion managers'(Bolton and Boyd, 2003) recognises the ability of individuals to move seamlessly between everyday social 'emotion work' and the more commercial 'emotional labour'. Studies have shown that emotional labour is also prevalent in the roles of managers (Humphrey, Pollack and Hawver, 2008; Iszatt-White, 2009; Ingram and Iszatt-White, 2012), yet research with regard to leadership practice is severely restricted (Humphrey, Pollack and Hawver, 2008; Gardner, Fischer and Hunt, 2009; Humphrey, Ashforth and Diefendorff, 2015).

Fundamental to emotional labour is the notion of acting. In setting out the ways in which emotional labour might be performed Hochschild (1983) differentiated 
between surface acting - 'deliberate emotional displays that are intended to deceive other persons about what the actor actually feels' (Gardner, Fischer and Hunt, 2009: 471) - and deep acting, where the aim is to 'deceiv[e] oneself as well as deceiving others' (Hampson and Junor, 2005:174, citing Hochschild, 1983: 33). Hochshild (1979: 553) likened surface acting to the English school of acting in which an outward demeanour is adopted to correspond to the intended emotions, whereas deep acting resembled the American or Stanislavsky school in which the actor guides their memories and feelings in such a way as to actually elicit the corresponding emotional expressions.

Surface acting is postulated as yielding feelings of inauthenticity (Humphrey, 2012), with emotional dissonance resulting as a consequence of the mismatch between displayed emotion and felt emotion, and the consequent diminished sense of self (Ashforth and Humphrey, 1993; Grundey, 1998; Ashforth and Tomiuk, 2000; Brotheridge and Lee, 2003). By contrast, deep acting is said to involve 'working on one's own thoughts and feelings in order to produce the required emotion and emotional impact' (Hampson and Junor, 2005:174). Through an effort to conjure up a sincere performance, it results in 'altering one's self' (Bolton and Boyd, 2003: 292) rather than the alienation from self said to result from the more cynical performance that is surface acting.

As noted above, emotional labour has been found to play a significant role in the undertaking of professional work in, for example, the work of teachers (Price, 2001) barristers (Harris, 2002), social workers (Bolton, 2005), nurses (Pisaniello, Winefield and Delfabbro, 2012) and human relations professionals (O’Brien and Linehan, 2014). In these contexts, as for organisational managers, the requirements of 
performing emotional labour have been found to be more complex, to require greater variety and judgement, and to be more value congruent (Iszatt-White, 2012) than in the largely formulaic enactment of 'service with a smile'.

Whilst the value congruence seen to underpin professional - and specifically leadership - emotional labour has in itself the potential to be less productive of stress and dissonance (Morris and Feldman, 1996; Grandey, Rupp and Brice, 2015), it nonetheless raises issues in relation to the juxtaposition of the requirement to perform emotional labour at the same time as wishing to appear and feel authentic. Much theorising and empirical work on authentic leadership is anchored in self-reports or follower perceptions of the occasions when genuine displays of emotion occur (Humphrey, Pollack and Hawver, 2008; Gardner, Fischer and Hunt, 2009). This represents recall of authenticity through an idealised lens that does not embrace the complexities of practice. Does this mean that leadership roles are fundamentally inauthentic when they are often, and arguably necessarily, required to perform emotional labour as a tool of accomplishing their goals (Iszatt-White, 2012)? And how do managers withstand the challenges of performing such 'necessary evils' and 'emotionally charged work' (Clair et al, 2015) as a recognised part of their professional roles? Gardner, Fischer and Hunt (2009: 479) ask 'is it possible for leaders to exhibit flexible emotional reactions across a wide variety of contexts without violating their sense of self?' They highlight that there is a dearth of empirical research at the level of practising managers and that rectifying this 'would help to clarify if authentic leadership represents an ideal that is difficult to attain in practice due to the complex emotional requirements imposed on leaders by contextual factors' (2009: 479). 
The lack of work in this area may be explained by Turnbull's observation that emotional labour 'is a phenomenon that few practising managers feel able to discuss, and yet it continues to be of vital importance for our understanding of organisations' (Turnbull, 2012: 153). Much has been written on authentic leadership yet little is known about how practising managers address the tension between the requirement to perform emotional labour and the idealised desire for relational transparency as a key component of authentic leadership. We suggest auto-ethnography as a methodology which offers significant benefits in accessing data on managers' experiences in this regard.

\section{Methodology}

This article is underpinned by two separate, but related, pieces of research. The first was an auto-ethnographic study of a specific leadership challenge undertaken by one of our Executive MBA students. It formed the basis of Matt's Masters dissertation, which was supervised by Steve. Marian, being most conversant with emotional labour in the context of leadership joined the research project to challenge and critique the initial and emerging insights. The evolutionary focus of study 1 (hence emotional labour was a finding rather than a premise of the study) and its necessarily limited scope (both in terms of organisational participation and the potential for gathering additional data) resulted in inherent data constraints which prompted Steve and Marian to seek additional data from the second study. This was conducted by Marian and two other colleagues: Matt did not participate in the second study. The methods utilised in each of the studies is set out below.

\section{Method for Study 1: Analytic Auto-ethnography}


The absence of auto-ethnographic accounts from managers is reflective of the wider lack of empirical work (Kempster and Stewart, 2010; Parry and Boyle, 2008). In part this also reflects the un-conventionality of auto-ethnography in management research where criticisms relate to rigour and notions of 'confessional tales' (Anderson, 2006), and being limited in their ability to understand the social world and move respective disciplines forward (Delamont, 2007). We have much sympathy with these concerns, and seek to address the same through the work of Anderson (2006) and the notion of analytic auto-ethnography. The absence of accounts from practising managers also reflects issues of confidentiality and ethical considerations. Additionally the creation of rigorous auto-ethnographic accounts from managers fundamentally relies on practitioners being able to be 'both inquirer and respondent' (Kempster and Stewart, 2010: 210).

We have been fortunate to have Matt participate in this research as the dissertation phase of his MBA studies. As his supervisor Steve met regularly with Matt over a period of months. They also corresponded by email and exchanged drafts and feedback for the dissertation itself. This co-constructed auto-ethnographic process supported the hyper-reflexivity needed in order to understand how a manager balances emotional labour and authenticity within leadership practice on an ongoing basis. Within the context of a critically reflective MBA programme, Matt was encouraged by Steve to critically apply notions of authenticity, professionalism, leadership, and so on derived from the programme content to his own experience of leading on a daily basis. This highlighted the contrast between his experience and the normative and idealised prescriptions of authentic leadership theory (see for example Avolio et al, 2004; Avolio and Gardner, 2005). Simply put, such normative theorising is not grounded in the everyday anxieties, upsets, conflicts of interest, fears, exhaustion, 
anger and despair that are the 'stuff' of leading and managing in organisations (Ford, 2006); the 'stuff' that often needs to be hidden away behind the acting façade (Hewlin, 2003) of being calm, in control, open, honest, and ethical.

Undertaken well an auto-ethnography 'require[s] self-questioning and confronting things [which] are less than flattering about oneself' (Eriksen, 2008: 623). To support this level of critical reflection, we have developed Anderson's (2006) notion of analytic auto-ethnography in conjunction with Kempster and Stewart's (2010) approach to processes of co-construction as outlined below:

Step 1: Matt's primary data consisted of emails, electronic diary entries and field notes made during the period of his dissertation research, alongside his immediate emotions. Together with his reflections on the tensions between displayed emotions and emotions felt, Matt used these to craft the first of many accounts making sense of his experiences.

Step 2: Engaging with Steve as his dissertation supervisor there was an iterative process of 'interrogation' of the emerging account using extant theory as prompts and provocations (Ramsey, 2011) in generating a co-constructed auto-ethnographic account (Kempster and Stewart, 2010).

Step 3: The emerging explanation was critiqued and challenged by Marian who was most conversant with emotional labour in the context of leadership.

Step 4: In order to retain the verisimilitude of the aesthetic account at the same time as limiting the vulnerability of Matt as both author and practising manager, a number of deletions and redactions were required.

In adopting an auto-ethnographic approach, we are keenly aware of the ethical issues raised for those involved. As a practising manager within the NHS Matt needed 
to retain the trust of his colleagues, and continue to be viewed as professional and competent, at the same time as writing about his own doubts and insecurities. He was also articulating what may be perceived by colleagues as 'inauthenticity' in relation to the ways in which he managed his emotions. Whilst seeking to develop the argument set out in this article, we were necessarily (and rightly) constrained in seeking further details and data which might have made Matt or his employer readily identifiable or compromised his status as a senior manager. Common to such research is the issue of disclosure in participant observation (Bryman and Bell, 2007). For example, none of Matt's colleagues were aware that he was keeping a diary of events and reflections as they happened, nor did they have the opportunity to consent to this in advance. Although anonymity is in part provided through omitting names and any unnecessary facts about those mentioned in the research there is the need to describe Matt's reactions and feelings in his relationships and interactions with particular key participants. Although consent has subsequently been granted for use of the data, obtaining this data without consent remains a lingering question mark of this approach. We are grateful to our co-author for such disclosure which enables us to vicariously stand in his shoes, to feel the emotional journey and allow for the development of theory on emotional labour and authenticity in the practice of leadership. Additionally we are grateful to the organisation for allowing us to explore this important area that would otherwise remain at best opaque and arguably taboo. It should also be noted that the auto-ethnographic study conducted by Matt received ethical approval from the relevant institutional committee prior to its commencement. For clarity, the potential for developing Matt's dissertation study into a journal article did not emerge until many months after his graduation. 
The auto-ethnographic account is presented as a series of diary vignettes in chronological order to allow the reader to get a sense of the ebb and flow of the emotional journey over the two-week period. We provide the commentary through Matt's voice in the first person.

The context for this study is the closure of an NHS hospital ward (referred to as Ward X), as implemented by Matt as a senior manager in a high-performing UK National Health Service (NHS) Foundation Trust Hospital. Leading up to the time period covered by this research the medical ward had experienced acute staffing problems. At the same time, the context for the NHS was one of significant financial pressure to the healthcare system overall, with this being manifested within the hospital sector through an increasing shift of resources into community-based services. As a result, hospitals and NHS Trusts we required to give serious consideration as to how best to redesign services and reduce expenditure on costly inpatient care, to mitigate the consequent reduction in income. It was in this context that the decision was taken to close Ward $\mathrm{X}$ for a period of months and to reassign staff to cover gaps throughout hospitals across the Trust. The decision was to be reviewed some months later, although with limited expectations that the ward would be reopened.

\section{Method for Study 2: Ethnographic Study}

Shaped by our findings from Matt's auto-ethnographic study, the second study sought to further explore issues arising from the juxtaposition of authentic leadership and emotional labour, and in particular the issue of relational transparency. Participants were drawn from two Masters level programmes within the institution - the Diploma for Hospice Leadership and the Executive MBA - via an open invitation to current participants and recent alumni. Matt was not part of this study. Data collection took 
the form of 36 interviews, 12 diary studies and 10 periods of observation undertaken with 12 study participants across of a range of public and private sector middle and senior managers. The interview, observational and diary data were collected over a period of approximately fifteen months, with each participant being interviewed multiple times. The interviews explored questions relating to how the research participants perceived authenticity in leadership, their experience of performing emotional labour within their leadership roles, and their sense of identity as leaders. Interview transcripts, diaries and field-notes were analysed through close reading and rereading (Ford, 2006), first by the researcher who had conducted that participants' suite of interviews, and then in collaboration with fellow investigators. This two-stage, comparative process resulted in the emergence of a rich and detailed resource in relation to discourses surrounding the ways in which emotional labour was performed in relation to perceptions of what it was to be a leader, the goals that were to be achieved and what it meant to feel (and appear) authentic in the face of these competing demands. Interview data relating to the participants interviewed by Marian are now drawn upon as representing parallel experiences and perspectives to those articulated by Matt in his auto-ethnographic study. Specifically, Marian extracted 128 extracts/vignettes from the 18 interviews she conducted within the wider study. These vignettes were coded under the themes which emerged from Matt's account of his own experience. Example vignettes have been selected as being most representative of the overall data set in this regard and hence most suitable for the elaboration of the two prominent themes arising from study 1, namely identification with leadership role and fidelity to purpose. We see the data from the second study as supporting that from the auto-ethnographic study in two key ways: firstly, it provides a degree of validation that Matt's experiences were not unique but are shared by other practising 
managers; and secondly, by explicitly asking participants about issues of relational authenticity and emotional labour (rather than having them as emergent themes) we were able to further explore the issues raised by Matt without unnecessarily trespassing on organisational confidentialities/identities. Whilst the specific nature of the study 2 data was not significantly different from that of study 1, we believe it adds value in terms of methodological robustness, and confidence that our findings resonate with the experiences of practising managers.

\section{Closing Ward X: Matt's Reflective Account}

For me, the biggest single revelation was that emotional labour and reconciling emotional dissonance was a way of life for me seeking to lead. It underpinned almost all of the interactions I had with colleagues at work, in one way or another. In the context of closing Ward X I now have come to see that emotional labour was ever present. Even in this email [the only one we can show] sent after a decision has been made to close the Ward, I now see that I was performing emotional labour.

\footnotetext{
From: Matt Brown

Sent: 05 [redacted] 15:22

To: [Redacted 1]; [Redacted 2]

Subject: Ward [X] - Quick Heads Up

Hi both

Just to let you know, have spoken to the following so far. [Redacted] was upset but knew it was on the cards, although surprised at the speed.

[Redacted] was a bit shocked and I would say slightly annoyed not to have been consulted. Asked if [Redacted] knew yet. [Redacted] seemed ok, clearly a bit upset. [Redacted sentence]. I tried to play a straight bat.

Speaking to [Redacted] after clinic (4pm-ish). I'll try to talk to [Redacted] after speaking with [Redacted]. Hope that is useful?

Matt
}

In hindsight, the way I expressed myself in this email is illustrative of the two themes that have emerged for me from the account: identification with role, and fidelity to purpose. 


\section{Theme \#1: Personal/professional expectations and identification with my role}

The range and abundance of communications through email persisted throughout the closure process. Only after exploring with Steve did I consider the emotions in play between myself, my peers and my line manager. Looking back now at this email I was seeking to present myself as a manager in control and calm, explaining the range of relational issues that could cause problems to the closure plans. However I must say that the email was masking the anxiety, fear and stress I was feeling as we started the process. The need for closing the ward and my commitment to the collective decision was not in doubt. We (the senior management team) all felt this was right, and this was my responsibility and my role to see through. I just knew how much the ward meant to people.

Four days after the email I held a meeting to advise colleagues operating the ward that it would be closed. Drawing from my diary:

Tuesday, $9^{\text {th }}$ : I paused and looked around the room, into the eyes of my team. Everyone was silent and all eyes were on me. A different scene flashed into my mind. It was an open plan office with about 20 desks, where I worked in a small consulting firm. That day, the Managing Director walked into the office, called us together and told us most of us would be made redundant. As he sat on a desk with a casual air, he broke the news as though he was telling us that we'd run out of teabags. I felt like I had been treated without respect and I was determined that would not be how my team would feel through this change. Back to now and we had to wait an agonising couple of minutes for the last members of staff to come into the room. A few people attempted small-talk, but it quickly faded and the atmosphere was tense. I took a deep breath and thought about the key messages that I needed to give. I felt nervous and sought to hide this and appear calm.

[Later] I felt exhausted ... My thoughts drifted back to the very challenging day I'd had, breaking bad news to my staff about the closure of their ward. At different points in the day, I had felt anxiety, loneliness, insecurity, embarrassment, frustration, excitement, apprehension, sympathy, anger, sadness, guilt, self-doubt and relief. Yet throughout I tried to exhibit a sense of 
calmness, certainty, confidence and conviction that the right thing was happening.

As I reflected on these diary comments it struck me (through conversation with Steve) that it spoke to a sense of identity with the leadership role. I wanted to come across as being calm and at the same time do the right thing. I needed to do this, it was my role. The 'stuff' I was dealing with and how I managed it, in terms of emotions, are part of that role. The next diary extract brings this to sharp attention through a day of meetings and having to continuously show emotions that I felt called upon to exhibit:

Tuesday, $9^{\text {th }}$ : I explained the context and delivered the news that the ward would close. There were gasps, particularly when I explained that this would be enacted from the coming Friday. I took in the shock, distress, tears, bewilderment and anger, trying to empathise with the emotions that the team were displaying but equally to maintain a calm, professional but positive tone. I found striking the right emotional tone deeply challenging, trying to be positive but not upbeat, optimistic but not patronising, calm but not dispassionate.

In essence it felt like being on a stage seeking to perform to the audience, my colleagues, offering up emotions they were seeking and expecting. Unlike being on a stage this went on for hours and hours. It was such a considerable challenge to sustain the acting out of desired emotions through countless interactions with colleagues whose eyes were ever present looking for authentic confirmation. The endless 'stage' performance of the role was exhausting and draining. Yet I did not feel this was inauthentic. Perhaps more of doing what was required of me and it had to be done: it was, indeed it is, my role.

Theme \#2: Fidelity to purpose - Aligning organisational purpose with personal/professional expectations in leader emotional labour 
Monday, 15 ${ }^{\text {th: }}$ As we assembled for the site briefing that morning, and ran through the devastation around us, I wanted the ground to open up and swallow me whole. All hell had broken loose after one of the worst weekends in recent years, with horrendous A\&E performance and multiple medical outliers, driven by nil bed capacity and massive staffing issues. Although I felt terribly guilty at having introduced extra pressure into the system, I nevertheless felt resolute that closing Ward X had been the right decision. All attention was on me as a senior clinician demanded to know why multiple staffing issues across the site weren't covered by the released staff from Ward $X$. Although the reality was quite simple - that all spare staff had been factored into rotas to cover vacancies and couldn't be pulled out at short notice - I felt my face burn red with embarrassment and became conscious of tiny beads of sweat developing on my brow as I tried to explain. I worked hard to display a sense of calm, but I knew that I was failing spectacularly. ... Looking back I recall the tension of trying to hold it together, to be the leader I wished I could or thought I should be.

Tuesday, 16 $^{\text {th }}$ : As I strode down the long corridor away from the site morning briefing I puffed out my cheeks and exhaled loudly. Although we were still under huge pressure and the day was shaping up to be horrendous I had responded much better to the same senior clinician. I worked hard emphasising the points that I felt strongly about, deliberately letting my tone and body language be robust, but respectful.

Thursday, $\mathbf{1 8}^{\text {th }}$ : Bed capacity, A\&E pressures and staffing were all returning to normal and the discussion was much calmer, less emotive. I was back to feeling calm which made me feel much more in sync with the messages I was giving out. As I slid into my car to drive home that night I just felt a deep sense of relief: the immediate pressures were well on the way to being resolved.

Although there were many moments of managing my emotional display it did not feel inauthentic. The emerging personal explanation was that when acting occurred it was in good faith. It was acting but this was not inauthentic. It drew from my commitment to what we had to do and alignment to my organisational role - it was expected of me and I expected it of myself.

\section{Role identification, purpose and authenticity}

The above accounts, alongside Matt's contemporaneous sense-making, have shown the emotional impact on him of the constant need to perform emotional labour within 
his leadership role, and how he manages such impact through his sense of being aligned to the need for the ward closure he is required to implement. For Matt, his sense of authenticity is sustained through his fidelity to the organisation's strategic objectives, his personal mores that he is doing the right thing and a strong sense of identification with his leadership role. His sense making is that he is a senior manager and such difficult decisions have to be seen through.

Matt's experience of leading the closure of Ward X suggests it is these key elements of role identification and fidelity to purpose that anchor a sense of authenticity as a leader, rather than the performance of relational transparency. His strong sense that the task of closing the ward fell rightly to him as a leader, and his self-expectations as to how he should conduct himself in the performance of this role, clearly mitigated the requirement to manage his emotions in the process. At the same time, the high degree of value congruence between the goals to be achieved and his own internalized role expectations enabled him to see the need to display unfelt-inthe-moment emotions in pursuance of a purpose to which he was committed as part of his role. Thus for Matt it is likely that the potential for estrangement between felt and expressed emotions is mitigated through his commitment to purpose, or the sense that, however difficult, it is 'work worth doing' (Conklin, 2012).

\section{Study 2 Findings}

The second study sought to understand whether this singular experience is common to other managers - connecting the 'particular' with the 'universal' (Van Maanen, 2011: 229). We now draw on independent data from this separate study conducted by Marian to validate our proposed reframing of authentic leadership.

\section{Theme \#1: Role identification and authenticity}


As with Matt, the managers in the second study articulated a strong sense of role identification which served to make otherwise unpalatable actions feel more authentic. They saw their leadership roles as part of who they were and hence less of an act or performance than might otherwise seem to be the case. So, for example, Karen saw connecting with staff emotionally as a performance in that it was conscious, but still felt it to be part of who she is as a leader:

A good part of leadership is how you make others feel. So it becomes part of that, really. So it's one and the same. It sounds like a performance. It probably sounds more like a performance because you have to think about it and be conscious of it, but actually it is really you in that you... if I affect other people and their emotions and they're focusing on me rather than the task in hand, that's not the right thing either. So it's probably one and the same, really. The more you do it the more it becomes you, anyway. (Karen, Director of Commercial Planning, NHS)

Similarly, David saw his leadership role as requiring him to 'amplify' emotions that were already a part of himself rather than to be something he wasn't. In both cases, there is a recognition that leadership is about others rather than yourself, and hence about providing them with what they need - motivation, encouragement, empathy, recognition, etc. - rather than about what is going on for you as a leader:

It's a very conscious effort so I'm always aware when I am doing it, for the large part. And there's almost an internal dialogue going on with knowing that you are operating outside of your default answer, if you like, and you've got to create that - I don't know - façade for want of a better word, to have that separation. I don't ... in the context of these things I think they are more exaggerating a feeling which is there somewhere already, it just is not - you wouldn't naturally do it to that level. And the empathy one naturally has for people and all the rest of it so it's not a complete false thing to do, it's just I'm mindful that I need to be more empathetic than I perhaps necessarily feel towards that individual. So, I don't think it's... it doesn't then create a feeling of dishonesty within your own actions, I guess, for me, because it's just having to amplify something. It is there somewhere, it's just you need to be showing more of it. (David, MD - IT Services) 
For all of the managers in the second study, value congruence played an explicit role in their sense of leadership authenticity, to a much greater extent than concerns over relational transparency, which were seldom mentioned:

To me it feels authentic because I'm not straying away from my values. I'm just anchoring them in the fact that as well as having strong values I have to do a job and my values aren't contradicted by my job, my job just needs to be grounded by those values. So, my job doesn't mean I have to do wrong things, it just means I have to do tough things. So, my values don't jump up and say "what you are doing now is wrong; don't do it" instead my values would say "what you are doing is difficult; be careful how you do it." (Donald, Commercial Director - IT Consultancy)

Along with many more we could have chosen, these extracts speak to role identification as ameliorating feelings of inauthenticity associated with the need to perform emotional labour within leadership work. The focus on the well-being and expectations of others (peers, subordinates, wider stakeholders and so on) is important in shaping how they see themselves and their role, and in underpinning their sense of authenticity.

\section{Theme \#2: Fidelity to purpose}

Also replicated in the data from the second study is Matt's sense of fidelity to purpose as a driving force behind whether or not managers feel authentic. Short term discomfort or 'inauthenticity' - for example, in not being able to express one's true feelings to colleagues - is overridden by a focus on the goal to be achieved and the strategies that might be required to achieve a successful outcome. Aileen articulates this sense of purpose as a moderator of feelings of inauthenticity when she describes herself as having to 'play the long game' when called upon to manage her emotions:

Yeah, well, one of the things that I realised recently, in everything I do I play the long game. It isn't a six-month or a twelve-month thing. It's years to get to where you want to get to so when I'm dealing with people they can really 
frustrate me sometimes and sometimes really make me quite cross but unless I feel that there is a benefit in them knowing that - and sometimes there is - I will essentially swallow that anger and that frustration and I will deal with them in a very kind of considered and managed way because at the end of the day it's about what I want to ultimately achieve. (Aileen, Senior Manager, Local Government)

The need to place emotions in a subordinate role to principles is also articulated by Aileen, when she shows herself willing to appear at a disadvantage if this is what it takes to get a job she believes to be worthwhile done:

So whatever goal I have in mind my emotions need to be balanced to that rather than my emotions controlling the goal, if you know what I mean, or influencing the end goal. So I will manage my emotions to achieve what I believe we need to achieve and that I suppose is because the principles that I have are more important than anything else. They will always override everything and anything. If I need to sit on my hands, if I need to look a bit stupid, if I need to play ignorant I'll do all those things if I believe that that is what is going to be for the betterment of the communities that we serve; and that is the overarching thing. How that affects me or makes me feel on that particular day, well, that's just part of the job. (Aileen, Senior Manager, Local Government)

The extracts of both themes thus offer a strong sense of resonance with Matt's experience. We did not seek to test our emergent themes as such. Rather the parallel research of study 2, exploring broad aspects of emotional labour, authenticity and identity, has confirmed that the 'particular' experience of the auto-ethnography has offered up a shared insight on the relationship of authenticity and emotional labour impacting on leadership practice. Study 2 gives confidence that aspects of role identification and fidelity to purpose are very present in the minds of practising managers and that they are significant in terms of how emotional authenticity is considered in the act of leading.

\section{Discussion}


In light of both studies we assert that relational transparency as a dimension of authentic leadership is problematic at the level of managers attempting to lead on a daily basis. We are not alone in problematizing authenticity and have earlier highlighted such concerns (Price, 2001; Michie and Gooty, 2005; Algera and LipsWiersma, 2012; Ford and Harding, 2011; Nyberg and Sveningsson, 2014). It is the complexities and ambiguities abounding in the attempted enactment of relational transparency that we now make salient. Viewing authenticity in the enactment of leadership through the lens of emotional labour suggests the near impossibility of relational transparency as a requirement of authentic leadership. Acting in accordance with everyday cultural display rules (Ekman, 1992) would preclude complete relational transparency: still more prohibitive to transparency are the necessities of confidentiality, professional expectations and occasionally self-protection attaching to most leadership roles and requiring the performance of emotional labour (IszattWhite, 2009, 2012). Both professional display rules and emotional labour preclude the degree of 'openness and truthfulness in one's close relationships' (Gardner et al, 2005: $357)$ or the level of 'selective self-disclosure' (2005: 357) suggested as constituting relational transparency. Similarly, being true to 'self-in-relationship' Algera and LipsWiersma (2012) is inhibited by these necessary elements of the enactment of leadership. This finding echoes the implausibility of authenticity that Ford and Harding (2011) assert is associated with a singular true self, and embraces a more complex and polyphonic sense of multiple displayed selves (Shotter, 2008). So, for example, our research participants might legitimately present themselves as strategic decision-makers, professional managers and empathetic human beings all in the space of one interaction, and legitimately feel that all these selves are authentic. The enactment of any or all of these 'selves' might require the management of emotions 
and hence preclude absolute transparency, and yet not be productive of feelings of inauthenticity. We thus suggest the emphasis that has been given to relational transparency within authentic leadership is misplaced and potentially harmful - setting up expectations of emotional behaviour that are often incompatible with role performance.

The development of the authentic leadership construct has not sought to understand how managers address two key interconnected aspects of its enactment in this regard. The first is the relational interdependence between emotional labour and authenticity (Bryant and Wolfram Cox, 2014) - the notion that, rather than being essentialist in nature, authenticity is 'a shifting and contextual phenomenon' (Butler, 2006: 14) that is 'defined positionally and relationally' (Bryant and Wolfram Cox, 2014: 2). On this basis, Bryant and Wolfram-Cox suggest that authenticity and emotional labour are 'intertwined rather than opposite' and question 'the privileging of authenticity over emotional labour' (2014: 6). The second is the often paradoxical nature of authenticity where managers have to be inauthentic, or at the very least 'restrain' their authenticity, in order to be 'good leaders', and thus perceived as authentic (Nyberg and Svenningsson, 2003). The focus on relational transparency suggests both of these aspects are deeply problematic for practising managers enacting leadership. In no small way we suggest that this formulation of AL theory has the potential to generate considerable 'authenticity dissonance' for practising managers seeking to perform to an impossible 'fantasy' (Sveningsson and Larson, 2006). We offer the two components of role identification and fidelity to purpose as alternative components of authentic leadership, which are better able to underpin the enactment of authenticity as a daily leadership behaviour. Both suggested components are more 
enduring and consistent, in contrast to the episodic and shifting feature that characterises leadership emotional labour thus undermining relational transparency.

The striking lack of grounded empirical research at the level of lived experience examining relational transparency has arguably led to AL being in tension with leadership practice. Reframing authenticity in leadership practice as role identification and fidelity to purpose aligns to the needs and demands of everyday organisational leadership because it is drawn from such practice. This is instantiated in the findings of our studies. The reflexive appreciation of Matt illustrates a manager coming to understand the implausibility of relational transparency and draws some reassurance that his practice of embracing emotional labour within his leadership behaviour is not inauthentic. His reframing, echoed prominently by the managers of study 2 , is that aspects of authenticity relate to role expectations and a complementary association with the fidelity to the purposes that his leadership is being directed towards.

\section{Conclusion}

Authenticity has become a most salient phenomenon of expected leader behaviour, notwithstanding the tension and dissonance surrounding leading authentically when understood through the lens of emotional labour. The experiences of both Matt and the participants of study 2 strongly suggest the prevalence of these issues in the minds and experiences of those undertaking leadership in the real world, and the importance of removing the burden of unrealistic expectations of romanticised notions of authenticity from their shoulders. Elsewhere, attention has been drawn to the potentially negative impact on manager well-being, effective decision-making and sustainable leader identities from the challenge of constant emotion management in the workplace through the everyday engagement with colleagues within leadership 
relationships (Iszatt-White and Ralph, 2016). These effects are of increased significance through their potential impact on team members and the wider organisation. There is an imperative for authenticity in leadership practice to be reexamined. The authentic leadership construct wholly underestimates the complex, nuanced and multidimensional character of authenticity in the context of leading, with the relational transparency component being particularly problematic. The persistence of discourses on authentic leadership assuming that the normative ideal of relational transparency (Walumbwa et al, 2008; Neider and Schriesheim, 2011), intended to guide the development of leadership, is misguided and potentially harmful. Examining authentic leadership through the lens of emotional labour provides an opportunity for beneficial revision to what it means to be authentic, with consequent benefits in terms of realistic, 'enactable' expectations for leadership practitioners.

Our findings are suggestive of the need for further research into the lived experience of authenticity by managers seeking to lead in a range of organisational contexts. The current research was inevitably narrow in its coverage, given the relatively small number of participants, and a broader understanding of managers experiences across a range of roles, functions and organisation types would instantiate the breadth and depth of the themes identified here. Such research may identify very different challenges to authenticity in a variety of contexts, at different managerial levels or in the profit versus not-for-profit sectors. There may be differences in how role identification or different perceptions of the worthiness of purpose is connected with situated leadership practice. What we believe they will confirm, however, is the impracticality and near impossibility of enacting relational transparency in the daily business of organisational leading, and the onerous burden this requirement places on managers seeking to live up to this normative ideal. We suggest that giving emphasis 
to 'fidelity to purpose' and 'role identification' may be a valuable counter-weight to the discourse for relational transparency promulgated by many in the leadership industry and a practical advance for those seeking to practise authenticity in leadership.

\section{References}

Algera, P.M. \& Lips-Wiersma, M. (2012). 'Radical authentic leadership: Co-creating the conditions under which all members of the organization can be authentic.' The Leadership Quarterly, 23: 118-131.

Anderson, L. (2006). 'Analytic auto-ethnography.' Journal of Contemporary Ethnography, 35(4): 373-395.

Ashforth, B. E., \& R.H. Humphrey, R.H. (1993). 'Emotional labor in service roles: The influence of identity.' The Academy of Management Review, 18(1): 88115.

Ashforth, B. I., \& Tomiuk, M.A. (2000). Emotional labour and authenticity: Views from .service agents. In S. Fineman (Ed.), Emotion in organization (2nd ed)., (pp. 184-205). London: Sage.

Avolio, B. J. \& Gardner, W.L. (2005). 'Authentic leadership development: Getting to the root of positive forms of leadership.' The Leadership Quarterly, 16(3): $315-338$.

Avolio, B.J., Gardner, W.L., Walumbwa, F.O., Luthans, F. \& May, D.R. (2004). 'Unlocking the mask: A look at the process by which authentic leaders impact follower attitudes and behaviors.' The Leadership Quarterly, 15(6): 801-823.

Bass, B.M. \& Steidlemeier, P. (1999) Ethics, character, and authentic transformational leadership. The Leadership Quarterly, 10(2): 181-217. 
Bolton, S.C. (2005). Emotion Management in the Workplace. Basingstoke: Palgrave Macmillan.

Bolton, S.C. \& Boyd, C. (2003). 'Trolley dolly or skilled emotion manager?Moving on from Hochschild's Managed Heart.' Work, Employment \& Society, 17(2): 289-308.

Brotheridge, C. M., \& Lee, R. T. (2003). 'Development and validation of the Emotional Labour Scale.' Journal of Occupational and Organizational Psychology, 76: 365-379.

Bryant, M. \& Wolfram Cox. J. (2014). 'Beyond authenticity? Humanism. psothumnaism and new organization development.' British Journal of Management, 25: 706-723.

Bryman, A. \& Bell, E. (2007). Business research methods. Oxford: Oxford University Press.

Butler, J. (2006). Gender Trouble: Feminism and the Subversion of Identity. New York: Routledge.

Clair, J.A., Ladge, J.J. \& Cotton, R. (2015) 'This is how we do it: How perceived prosocial impact offsets negative personal outcomes associated with carrying out necessary evils.' Journal of Management Inquiry, published online November 18, 2015.

Conklin, Thomas A. (2012) 'Work worth doing: A phenomenological study of the experience of discovering and following one's calling.' Journal of Management Inquiry, 21(3): 298-317.

Cunliffe, A. (2002) 'Reflexive Dialogical Practice in Management Learning.' Management Learning, 33(1): 35-61. 
Delamont, S. (2007). 'Arguments against auto-ethnography.' Qualitative Researcher, 4: $2-4$.

Eagly, A.H. (2005). 'Achieving relational authenticity in leadership: Does gender matter?' The Leadership Quarterly, 16(3): 459-474.

Ekman, P. (1992). Facial expressions of emotion: New findings, new questions. Psychological Science, 3(1): 34-38.

Eriksen, M. (2008). 'Leading adaptive organizational change: Self-reflexivity and selftransformation.' Journal of Organizational Change Management, 21(5): 622640.

Ford J. \& Harding, N. (2011). 'The impossibility of the true self of authentic leadership.' Leadership, 7(4): 463-479.

Ford J. (2006) Discourses of leadership: Gender, identity and contradiction in a UK public sector. Leadership, 2(1): 77-99.

Gardner, W.L., Fischer, D. \& Hunt, J.G. (2009). 'Emotional labor and leadership: A threat to authenticity?' The Leadership Quarterly, 20(3): 466-482.

Gardner, W.L., Avolio, B.J., Luthans, F., May, D.R. \& Walumbwa, F. (2005) "Can you see the real me?' A self-based model of authentic leader and follower development.' The Leadership Quarterly, 16 (3): 343-372.

George, W. (2003) Authentic leadership: Rediscovering the secrets to creating lasting value. San Francisco, C.A: Jossey-Bass,

Grandey, A.A. (2000). Emotional regulation in the workplace: A new way to conceptualize emotional labor. Journal of Occupational Health Psychology, 5(1): 95-110. 
Hampson, I. \&. Junor, A. (2005). 'Invisible work, invisible skills: Interactive customer service as articulation work.' New Technology, Work and Employment, 20(2): $166-181$.

Harris, L.C. (2002). 'The emotional labour of barristers: An exploration of emotional labour by status professionals.' Journal of Mangement Studies, 39(4): 553-584.

Harter, S. (2002). Authenticity. In C.R. Snyder \& S.J. Lopez (eds) Handbook of positive psychology. New York, Oxford University Press. (pp. 382-394).

Hewlin, P.F. (2003). 'And the award for best actor goes to ...: Facades of conformity in organizational settings.' Academy of Management Review, 28(4): 633-642.

Hochschild, A. R. (1983). The Managed Heart: Commercialization of Human Feeling. Berkeley: University of California Press.

Hochschild, A.R. (1979) Emotion work, feeling rules and social structure. American Journal of Sociology, 85: 551-575.

Humphrey, R. H. (2012). How leading with emotional labour creates common identities. In M. Iszatt-White (ed), Leadership as Emotional Labour : Management and the 'Managed Heart', (pp. 56-79). Abingdon: Taylor and Francis.

Humphrey, R.H., Ashforth, B.E., \& Diefendorff, J.M. (2015). 'The bright side of emotional labour.' Journal of Organizational Behavior, 36(6):_ 749-769

Humphrey, R.H., Pollack, J.M., \& Hawver, T. (2008). 'Leading with emotional labor.' Journal of Managerial Psychology, 23(2): 151-168.

Ilies, R., Morgeson, F.P. \& Nahrgang, J.D. (2005). 'Authentic leadership and eudaemonic well-being: Understanding leader-follower outcomes.' The Leadership Quarterly, 16(3): 373-394. 
Ingram, S. \& Iszatt-White, M. (2012). Truth, authenticity and emotional labour: a practitioner's perspective. In M. Iszatt-White (ed), Leadership as Emotional Labour : Management and the 'Managed Heart', (pp, 129-152). Abingdon: Taylor and Francis.

Iszatt-White, M. and Ralph, N. (2016) Who contains the container? Creating a holding environment for practising leaders. British Academy of Management Conference. Newcastle, 6th - 8th September 2016.

Iszatt-White, M. (2012). Leadership as emotional labour: so what's new? In M. IszattWhite (Ed.), Leadership as Emotional Labour: Management and the 'Managed Heart', 14-36. Abingdon: Taylor and Francis.

Iszatt-White, M. (2009). 'Leadership as emotional labour: The effortful accomplishment of valuing practices.' Leadership, 5(4): 447-467.

Kempster, S. \& Stewart, J. (2010). 'Becoming a leader: A co-produced autoethnographic exploration of situated learning of leadership practice.' Management Learning, 41(2): 205-219.

Kernis, M.H. \& Goldman, B.M. (2006). 'A multicomponent conceptualization of authenticity: Theory and research.' Advances in Experimental Social Psychology, 38: $283-357$

Lawler, J. \& Ashman, I. (2012). 'Theorizing leadership authenticity: A Sartrean perspective.' Leadership, 8(4): 327-344.

Luthans, F. \& Avolio, B.J. (2003). Authentic leadership: A positive developmental approach. K.S. Cameron, J.E. Dutton, R.E. Quinn (eds.), Positive organizational scholarshiP (pp. 241-261). Barrett-Koehler, San Francisco (2003), 
Michie, S. \& Gooty, J. (2005). 'Values, emotions and authenticity: Will the real leader please stand up?' The Leadership Quarterly, 16: 441-457.

Neider, L.L. \& Schriesheim, C.A. (2011). 'The Authentic Leadership Inventory (ALI): Development and empirical tests.' The Leadership Quarterly, 22(6): 11461164.

Nyberg, D. \& Sveningsson, S. (2014). 'Paradoxes of authentic leadership: Leader identity struggles.' Leadership, 10(4): 437-455.

O'Brien, E. \& Linehan, C. (2014). 'A balancing act: emotional challenges in the HR role.' Journal of Management Studies, 51(8): 1257-1285.

Parry, K.W. \& Boyle, M. (2009). Organizational auto-ethnography. In D. Buchanan and A. Bryman (eds.) The Sage Handbook of Organizational Research Methods, (pp. 690-702). London: Sage.

Pisaniello, S.L., Winefield, H.R. \& Delfabbro, P.H. (2012). 'The influence of emotional labour and emotional work on the occupational health and wellbeing of South Australian hospital nurses.' Journal of Vocational Behavior, 80(3): $579-591$

Price, H. (2001). 'Emotional labour in the classroom: A psychoanalytic perspective.' Journal of Social Work Practice, 15(2): 161-180.

Rafaeli, Anat and Sutton, Robert I. (1987) Expression of emotion as part of the work role. Academy of Management Review, 12(1): 23-37.

Ramsey, C. (2011). 'Provocative theory and a scholarship of practice.' Management Learning, 42(5): 469-483.

Shamir, B. \& Eilam, G. (2005). What's your story? A life-stories approach to authentic leadership development. Leadership Quarterly, 16, 395-417. 
Shotter, J. (2008). 'Dialogism and polyphony in organizing theorizing in organization studies: action guiding anticipations and the continuous creation of novelty.' Organization Studies, 29(4): 501-524.

Sparrowe, R.T. (2005) Authentic leadership and the narrative self. The Leadership Quarterly, 16 (3): 419-439. Stormer, F. \& Devine, K. (2008). 'Acting at work: facades of conformity in academia.' Journal of Management Inquiry, 17(2): $112-134$.

Stefan Sveningsson, S. and Larsson, M. (2006) 'Fantasies of Leadership: Identity Work' Leadership, 2(2): 203-224.

Tourish, D. (2015) 'Some announcements, reaffirming the critical ethos of Leadership, and what we look for in submissions.' Leadership, 11(2): 135-141.

Turnbull, S. (2012). Middle managers' emotional labour in disseminating culture change: a case study in the requirement for changing values. In M. IszattWhite (ed), Leadership as Emotional Labour : Management and the 'Managed Heart', (pp.153-172). Abingdon: Taylor and Francis.

Van Maanen, J. (2011). 'Ethnography as work: some rules of engagement.' Journal of Management Studies, 48(1): 218-234.

Walumbwa, F., Avolio, B.J., Garnder, W.L., Wernsing, T.S. \& Peterson, S.J. (2008). 'Authentic leadership: Development and validation of a theory-based measure.' Journal of Management, 34(1): 89-125. 